\title{
Effect of low irradiance on the photosynthetic performance and spiking of Phalaenopsis
}

\author{
Y.-C. LIU*, C.-H. LIU**, Y.-C. LIN ${ }^{* *}$, C.-H. LU**, W.-H. CHEN ${ }^{* * *}$, and H.-L. WANG ${ }^{*, * *,+}$ \\ Department of Life Sciences*, Institute of Biotechnology**, National University of Kaohsiung, No. 700 Kaohsiung \\ University Rd. Nan-Tzu District 811, Kaohsiung, Taiwan, Republic of China \\ Orchid Research Center, National Cheng Kung University, Tainan, District 701, Taiwan, Republic of China**
}

\begin{abstract}
Lowering irradiance can delay the flower stalk, i.e., spike development, in order to schedule flowering time of Phalaenopsis; however, the effect on photosynthetic performance and spiking inhibition remains poorly understood. We compared light and shade treatments of Phalaenopsis aphrodite subsp. formosana in order to determine how limiting light affects day-night changes in the photosynthetic capacity of leaves and the carbon pool of leaves and stems resulting in delayed spiking. The low irradiance treatment $\left[20 \mu \mathrm{mol}\right.$ (photon) $\left.\mathrm{m}^{-2} \mathrm{~s}^{-1}\right]$ for six weeks did not affect potential functions of photosynthetic apparatus estimated by chlorophyll $a$ fluorescence analysis, but it significantly reduced the net $\mathrm{CO}_{2}$ uptake and $\mathrm{O}_{2}$ evolution rates, carbohydrate and organic acid concentrations, and amplitudes of CAM activity in new and fully expanded leaves of Phalaenopsis and delayed the spiking compared with the control kept at $150 \mu$ mol(photon) $\mathrm{m}^{-2}$ $\mathrm{s}^{-1}$. The shortened stem contained a remarkably high sucrose concentration, accounting for more than $80 \%$ of total soluble sugars for both treatments throughout the day. Moreover, the sucrose concentration was unaffected by the lowering of irradiance. The relationship between the sucrose content and spiking seemed to be loose; the major factor(s) for spiking in Phalaenopsis remained to be ascertained as the flower stalk bud is attached to the shortened stem.
\end{abstract}

Additional key words: CAM; carbohydrate; chlorophyll fluorescence; flower stalk; gas exchange; oxygen evolution.

\section{Introduction}

Phalaenopsis orchids are popular and valued potted ornamental plants worldwide for their beautiful longlasting flowers with a variety of shapes, sizes, and colors (Endo and Ikusima 1992, Chugh et al. 2009). In order to meet market demands, flowering time must be precisely scheduled. One of key steps in regulating Phalaenopsis flowering is to control the emergence of the flower stalk or spiking.

Lowering of irradiance is a known strategy to delay spiking in Phalaenopsis (Kubota and Yoneda 1993, Wang 1995, Wang 1997, Hisamatsu et al. 2001, Liu et al. 2010, Wu et al. 2013). For example, Wang (1995) demonstrated that the spiking of Phalaenopsis cultured in a growth chamber was inhibited under irradiance of $8 \mu \mathrm{mol}$ (photon) $\mathrm{m}^{-2} \mathrm{~s}^{-1}$ during a 12-h photoperiod or complete darkness for 6 weeks. Many studies have mentioned that the decrease in the sucrose concentration under lower irradiance may be an inhibitory signal for spiking, but their deduction was only based on the results from studies where new and fully expanded leaves were used (Konow and Wang 2001, Kataoka et al. 2004, Guo and Lee 2006, Tsai et al. 2008, Wu et al. 2013).

Phalaenopsis is a monopodial orchid with thick leaves alternating on each side of the plant and the bases

Received 30 March 2015, accepted 6 October 2015, published as online-first 19 October 2015.

${ }^{+}$Corresponding author; phone: 886-7-5919230, fax: 886-7-5919404, e-mail: hlwang@nuk.edu.tw

Abbreviations: $\mathrm{Chl}$ - chlorophyll; $\mathrm{CK}$ - control; $\mathrm{F}_{0}$ - minimal fluorescence yield of the dark-adapted state; $\mathrm{F}_{0}{ }^{\prime}-$ minimal fluorescence yield of the light-adapted state; $F_{m}$ - maximal fluorescence yield of the dark-adapted state; $F_{m}{ }^{\prime}-$ maximal fluorescence yield of the light-adapted state; $F_{s}$ - steady-state fluorescence yield; $F_{v}$ - variable fluorescence; $F_{v} / F_{m}$ - maximum quantum efficiency of PSII photochemistry; FM - fresh mass; $g_{s}$ - stomatal conductance; NPQ - nonphotochemical quenching; $P_{\mathrm{N}}-$ net $\mathrm{CO}_{2}$ assimilation rate; $\mathrm{SH}$ - shade; ФPSII - actual photochemical efficiency of PSII.

Acknowledgements: The authors would like to thank Prof. Jong-Ching Su for reviewing the manuscript. We sincerely thank Taiwan Sugar Research Institute for lending the LI-6400 ( $L i$-Cor Inc., Lincoln NE, USA) and Prof. Yau-Lun Kuo (Graduate Institute of Bioresources, National Pingtung University of Science and Technology) for his helpful instruction on gas exchange measurements. This work was supported by the grant NSC 98-2313-B-390-001-MY3 from the National Science Council, Executive Yuan, Taiwan.

"C The Author(s)." This article is published with open access at link.springer.com 
of leaves are connected to a shortened stem. One or two dormant spike buds emerge from the stem at the base of the third to fourth leaves that are numbered basipetally from the aerial portion of the plant (Sakanishi et al. 1980). Although the leaf is the site of light perception, it is reasonable to speculate that the signal in the stem of Phalaenopsis is involved more directly with spike development than with the leaf, because the spike bud is connected with the stem. To our knowledge, little is known about the relationships between carbohydrates, particularly, sucrose concentrations in the stem, and spiking inhibition of Phalaenopsis subjected to low irradiance.

A reduction in photosynthesis by lowering of irradiance is axiomatic. Photosynthetic capacity can be investigated by noninvasive methods, such as net $\mathrm{CO}_{2}$ assimilation rate and chlorophyll (Chl) $a$ fluorescence, and the invasive method, e.g., $\mathrm{O}_{2}$ evolution rate. Phalaenopsis is an obligate CAM plant with a day-night fluctuation of

\section{Materials and methods}

Plant material and growth conditions: Mature $P$. aphrodite subsp. formosana plants were purchased from the Wusulin Farm of the Taiwan Sugar Corp., Tainan County, southern Taiwan $\left(23^{\circ} 34^{\prime} \mathrm{N}, 120^{\circ} 38^{\prime} \mathrm{E}\right)$ and transplanted in transparent plastic pots $(10.5 \mathrm{~cm})$ filled with sphagnum moss in an environment-controlled greenhouse at $28.0 \pm 1.2^{\circ} \mathrm{C}$ for four months in order to inhibit spiking. The plants with six leaves were then kept for six weeks in a growth chamber under a photoperiod with $14 \mathrm{~h}$ of light (06:00-20:00) and $10 \mathrm{~h}$ of dark (20:00-06:00) with 150 and $20 \mu \mathrm{mol}$ (photon) $\mathrm{m}^{-2} \mathrm{~s}^{-1}$ of PAR supplied with cool-white fluorescence tubes (F20T12, GE Inc., Schenectady, NY, USA) at the tops of the plants for control (CK) or shade (SH) treatment, respectively. The day and night temperature for both treatments were $28.5 \pm$ 0.4 and $20.5 \pm 0.4^{\circ} \mathrm{C}$, respectively. The plants were irrigated once a week, alternating between water and Peters fertilizer $\left(1.0 \mathrm{~g} \mathrm{~L}^{-1}\right)$ (Hyponex Corp., Marysville, $\mathrm{OH}$, USA) at about $1 \mathrm{mS} \mathrm{cm} \mathrm{cm}^{-1}$, as measured with a conductivity meter (Model 3250, JENCO Inc., CA, USA).

Spiking characteristics: Spiking was defined as the appearance of a flower stalk greater than $0.5 \mathrm{~cm}$ in length. We performed three batch experiments, with 12 individual plants each, to determine the spiking ratio for each treatment. The spike number represented the number of the flower stalks per spiking plant and the spike length was measured from the base of the flower stalk at the junction between the base of the leaves and shortened stem to the apex of the flower stalk (Liu et al. 2013).

Sampling procedure: The leaves were numbered basipetally and the second leaf $\left(c a .85 \mathrm{~cm}^{2}\right)$ was considered a newly expanded leaf and had approximately double the size of the first leaf. After noninvasive $\mathrm{Chl} a$ fluorescence and gas exchange analyses (see below), the second leaf photosynthetic characteristics: malic acid accumulation with open stomata during the night time and starch deposition with closed stomata during the day time, which implies that the maximum malate and starch contents should occur at dawn and dusk, respectively. On the contrary, the minimum malate and starch contents are exhibited at dusk and dawn, respectively (Endo and Ikusima 1989, Guo and Lee 2006, Chen et al. 2008, Pollet et al. 2011). Hence, we examined the diurnal changes in photosynthetic capacity of Phalaenopsis exposed to lowering $\left[20 \mu \mathrm{mol}\right.$ (photon) $\mathrm{m}^{-2} \mathrm{~s}^{-1}$ ] and control [150 $\mu \mathrm{mol}\left(\right.$ photon) $\mathrm{m}^{-2} \mathrm{~s}^{-1}$ ] irradiances, together with the daynight changes of the contents of photosynthesis-related metabolites in the new and fully expanded leaf and stem to clarify how limiting light affects the day-night variations in photosynthetic performance, and the cause-and-effect of photosynthates on the spike development of Phalaenopsis.

from different plants was removed at four sampling points: midnight (00:00 h), dawn $(06: 00 \mathrm{~h})$, midday $(12: 00 \mathrm{~h})$, and dusk (18:00 h) [phase I, II, III, and IV, respectively, see Osmond (1978) for a definition of the four CAM-phases] for metabolite analysis. Leaf discs $\left(c a .0 .28 \mathrm{~cm}^{2}\right)$ were cut from the middle and approximately $0.5 \mathrm{~cm}$ away from the main vein of the second leaf with a cork borer (Chen et al. 2008). After all leaves were completely removed, a knife was used to harvest the stem from the junction between the base of the flower stalk bud and the shortened stem, and the flower stalk was removed (Liu et al. 2013). The leaf discs and stems were weighed and frozen in liquid $\mathrm{N}_{2}$ for analysis.

Metabolite analyses: To determine concentrations of organic acids, leaf discs were homogenized and extracted with distilled water at $100^{\circ} \mathrm{C}$ (Callaway et al. 1997). Organic acids were analyzed by anion exchange chromatography (AS-11, Dionex Corporation, Sunnyvale, CA, USA) using 5-100 $\mathrm{mM} \mathrm{NaOH}$ for linear gradient elution and the eluted acids were quantified using a Dionex electrochemical detector (ED50, Dionex Corporation, Sunnyvale, CA, USA ) (Chen et al. 2008). The contents of organic acids (malate and citrate) were calculated from the integrated peak area of the corresponding standards, total organic acid $\left[\mu \mathrm{g} \mathrm{g}^{-1}\right]=$ (organic acid content from the corresponding standard $[\mu \mathrm{g}] \times$ total extract volume $[\mathrm{mL}] /$ analysis volume $[\mathrm{mL}]$ )/fresh mass (FM) [g]. The amount of malic acid accumulated nocturnally can be estimated by its content at 06:00 minus that at 18:00 (Popp et al. 2003).

To determine soluble sugar concentrations, leaf discs and stems were separately homogenized and extracted with $80 \%$ (v/v) ethanol at $80^{\circ} \mathrm{C}$ (Chen et al. 2008). Sugars were separated on a CarboPac PA10 column (Dionex Corporation, Sunnyvale, CA, USA) with $18 \mathrm{mM} \mathrm{NaOH}$ as an eluent and quantified by use of a Dionex pulsed 
amperometric detector (Chen et al. 2008). The contents of soluble sugars (glucose, fructose and sucrose) were calculated from the integrated peak area of the corresponding standards, total soluble sugar $\left[\mu \mathrm{g} \mathrm{g}^{-1}\right]=$ (soluble sugar content from the corresponding standard $[\mu \mathrm{g}] \times$ total extract volume $[\mathrm{mL}]$ /analysis volume $[\mathrm{mL}]$ )/fresh mass (FM) [g]. Sediment was digested with a mixture of pullulanase and amyloglucosidase and the released glucose was estimated by a glucose oxidase and peroxidase method to determine the starch content (Chen et al. 2008). The amount of starch deposited at day time can be estimated by its content at 18:00 h minus that at 06:00 h (Popp et al. 2003).

Chl $\boldsymbol{a}$ fluorescence measurements were performed using a pulse-amplitude modulation fluorometer (PAM-210, Walz, Effeltrich, Germany). The second leaf was acclimated to dark for at least $30 \mathrm{~min}$. The minimal fluorescence $\left(\mathrm{F}_{0}\right)$ was determined under a radiation low enough $\left[<0.2 \mu \mathrm{mol}\right.$ (photon) $\left.\mathrm{m}^{-2} \mathrm{~s}^{-1}\right]$ to induce any significant variable fluorescence. The maximal fluorescence value $\left(\mathrm{F}_{\mathrm{m}}\right)$ was determined by a saturating pulse (SP) with 3,500 $\mu$ mol(photon) $\mathrm{m}^{-2} \mathrm{~s}^{-1}$ on the dark-adapted leaf. Then, the leaf was continuously illuminated with an ambient actinic light of about 150 and $20 \mu \mathrm{mol}$ (photon) $\mathrm{m}^{-2} \mathrm{~s}^{-1}$ for $\mathrm{CK}$ and $\mathrm{SH}$ treatment, respectively, to reach a stable fluorescence level $\left(F_{s}\right)$. Thereafter, a second SP was imposed to determine the maximal fluorescence value on the light-adapted leaf $\left(\mathrm{F}_{\mathrm{m}}{ }^{\prime}\right)$. In the present study, we adopted the maximum quantum yield $\left(\mathrm{F}_{\mathrm{v}} / \mathrm{F}_{\mathrm{m}}\right)$ calculated as $1-\mathrm{F}_{0} / \mathrm{F}_{\mathrm{m}}$ to estimate the potential yield of PSII photochemical reactions (Roháček and Barták 1999, Baker 2008 ). The actual quantum yield of PSII ( $\left.\Phi_{\text {PSII }}\right)$ was calculated as $1-\mathrm{F}_{\mathrm{s}} / \mathrm{F}_{\mathrm{m}}$ ' in order to estimate the fraction of light absorbed by PSII antennae utilized in PSII photochemistry (Genty et al. 1989, Demmig-Adams et al. 1996). The actual nonphotochemical quenching (NPQ)

\section{Results}

Flower stalk development: When grown under $\mathrm{SH}$ conditions for six weeks, plants exhibited a spiking ratio of $18 \%$, with the mean spike number of 1.0 per a spiking plant, and a mean spike length of $0.6 \mathrm{~cm}$ (Table 1). These results were all significantly lower than those for the CK treatment with almost all plants exhibiting spiking with the mean spike number of 1.7 per the spiking plant, and the mean spike length of $4.4 \mathrm{~cm}$ (Table 1). Evidently, lowering of the irradiance delayed the flower stalk development.

Chl $\boldsymbol{a}$ fluorescence: During the $\mathrm{CK}$ treatment, $\mathrm{F}_{\mathrm{v}} / \mathrm{F}_{\mathrm{m}}$ slightly decreased during the day time and reached a minimum at 18:00; then gradually increased during the night time (Fig. 1A). Likewise, this trend also occurred in the $\mathrm{SH}$ plants; the mean $\mathrm{F}_{\mathrm{v}} / \mathrm{F}_{\mathrm{m}}$ remained at $0.80-0.82$ was calculated by $F_{m} / F_{m}{ }^{\prime}-1$ as the estimate of the dissipation of absorbed energy as heat in PSII antenna complexes in the light-adapted state (Bilger and Björkman 1990, Demmig-Adams et al. 1996).

Gas exchange: The stomatal conductance $\left(g_{\mathrm{s}}\right)$ and photosynthetic gas exchange of the second leaf was measured by use of an infrared gas analyzer system (LI-6400, $\mathrm{Li}$-Cor Inc., Lincoln NE, USA). External air was scrubbed of $\mathrm{CO}_{2}$ and mixed with a supply of pure $\mathrm{CO}_{2}$ to create a standard concentration of $400 \mu \mathrm{mol} \mathrm{mol}{ }^{-1}$. Flow rate was $500 \mu \mathrm{mol} \mathrm{s}^{-1}$. Measurements were made at PAR of 150 and $20 \mu$ mol(photon) $\mathrm{m}^{-2} \mathrm{~s}^{-1}$ for the $\mathrm{CK}$ and $\mathrm{SH}$ treatments, respectively; provided by a light emitting diode source (6400-02, Li-Cor Inc., Lincoln NE, USA), attached to the sensor head during day time, and the light source was turned off during night time.

$\mathrm{O}_{2}$ evolution rate: The photosynthetic $\mathrm{O}_{2}$ evolution rate of the second leaf was measured using an oxygen electrode (Leaflab 1 System, Hansatech, UK). The sample leaves were cut at three time points: at dawn $(06: 00 \mathrm{~h})$, at midday $(12: 00 \mathrm{~h})$, and at dusk (18:00 h). Each leaf was cut by a sharp razor and leaf discs $\left(c a .10 \mathrm{~cm}^{2}\right)$ were punched out at the middle and away from main veins of the leaf by a borer and immediately placed into the electrode chamber in a closed system of air with $1 \%(\mathrm{v} / \mathrm{v}) \mathrm{CO}_{2}$ supplied with $0.2 \mathrm{ml}$ of $1 \mathrm{M}$ sodium bicarbonate solution. The $\mathrm{O}_{2}$ evolution rate was measured under air temperature of $28^{\circ} \mathrm{C}$ and irradiance at about 150 and $20 \mu \mathrm{mol}\left(\right.$ photon) $\mathrm{m}^{-2} \mathrm{~s}^{-1}$, respectively.

Statistical analysis: Data are means \pm SE. The data were subjected to one-way analysis variance $(A N O V A)$ and the differences between means were measured at the $5 \%$ probability level using Fisher's protected least significant difference (LSD) test (CoHort Software, Monterey, CA).

during the dark period (22:00-03:00 h), slightly decreased to $0.76-0.79$ during the light period (09:00-18:00 h), and both treatments showed limited changes throughout the day (Fig. 1A).

As compared to $\mathrm{F}_{\mathrm{v}} / \mathrm{F}_{\mathrm{m}}$, $\Phi_{\text {PSII }}$ showed a distinct daynight fluctuation (Fig. 1B). Under the CK treatment, it showed approximately $37 \%$ decrease from $12: 00$ to 18:00 $\mathrm{h}$, then remained at low levels during the dark period, and peaked at 09:00 and 12:00 h. In contrast, under the SH treatment, the high values were similar to $\mathrm{CK}$ and remained such during the day time, while the lower values appeared during the dark period. The major disparity between the CK and $\mathrm{SH}$ treatments occurred at 18:00 h, $\mathrm{CK}$ was significantly lower than that under SH. 
Table 1. Effect of lower irradiance on the spiking characteristics of Phalaenopsis aphrodite. Data are means \pm SE of 36 individual plants from 3 batch experiments, with 12 individual plants each. Different letters show significant difference between control and shade treatments $(p \leq 0.05)$.

\begin{tabular}{llll}
\hline Condition & $\begin{array}{l}\text { Spiking ratio } \\
{[\%]}\end{array}$ & $\begin{array}{l}\text { Spike number } \\
\text { per spiking plant }\end{array}$ & $\begin{array}{l}\text { Spike length } \\
{[\mathrm{cm}]}\end{array}$ \\
\hline Control & $94 \pm 6^{\mathrm{a}}$ & $1.7 \pm 0.2^{\mathrm{a}}$ & $4.4 \pm 0.8^{\mathrm{a}}$ \\
Shade & $8 \pm 14^{\mathrm{b}}$ & $1.0 \pm 0.0^{\mathrm{b}}$ & $0.6 \pm 0.1^{\mathrm{b}}$ \\
\hline
\end{tabular}

Similar to $\Phi_{\text {PSII }}$ NPQ values also showed a marked day-night fluctuation with a peak during the night time and the lowest values during the day time for both treatments. A marked difference also appeared at 18:00 h, where CK values were significantly higher than those under $\mathrm{SH}$ (Fig. 1C).

Gas exchange: During the CK treatment, $g_{\mathrm{s}}$ exhibited a significant day-night fluctuation. Namely, stomata started opening after 15:00 $\mathrm{h}$ and remained opened throughout the night time, then closed from 09:00 to 15:00 h (Fig. 2A). Similar day-night fluctuation of $g_{\mathrm{s}}$ was reported in our previous work (Chen et al. 2008). However, under the SH treatment, the stomata opened only at night and remained closed throughout the day time with significantly decreased $g_{\mathrm{s}}$ compared with CK.

Similarly, the pattern of net $\mathrm{CO}_{2}$ uptake rate $\left(P_{\mathrm{N}}\right)$ (Fig. 2B) corresponded well with $g_{\mathrm{s}}$ (Fig. 2A). During the $\mathrm{CK}$ treatment, $\mathrm{CO}_{2}$ fixation slightly increased during the late afternoon, with a peak at 21:00, then gradually decreased and became zero in the early morning. In contrast, during the $\mathrm{SH}$ treatment, $\mathrm{CO}_{2}$ fixation proceeded only during the night time (Fig. $2 B$ ). The total net carbon gain estimated by integrating the $\mathrm{CO}_{2}$ uptake rate curve for the CK treatment was $c a .234 .7 \mathrm{mmol} \mathrm{m}^{-2}$, significantly higher than that of the $\mathrm{SH}$ treatment, which was $c a$. $32.6 \mathrm{mmol} \mathrm{m}^{-2}$.

$\mathrm{O}_{2}$ evolution: In both treatments, oxygen consumption occurred at $06: 00 \mathrm{~h}$ and a peak of $\mathrm{O}_{2}$ evolution was reached at 12:00 $\mathrm{h}$. The value was four times higher in the CK than that of SH plants (Table 2). During transition from day to night $(18: 00 \mathrm{~h}), \mathrm{O}_{2}$ evolution significantly decreased in plants of both treatments and some SH plants even started consuming $\mathrm{O}_{2}$.

Organic acids: During the $\mathrm{CK}$ treatment, the highest malate concentration, $c a .7 .1 \mathrm{mg} \mathrm{g}^{-1}(\mathrm{FM})$, was reached at 06:00 $\mathrm{h}$ and the lowest, $c a .0 .3 \mathrm{mg} \mathrm{g}^{-1}(\mathrm{FM})$, was found at 18:00, which showed steady decarboxylation from $06: 00$ to 18:00 $\mathrm{h}$ and a distinct nocturnal accumulation (Fig. $3 A$ ). Under the SH treatment, the malate concentration was similar to the CK concentration at 00:00 and 12:00 h. However, at 06:00 and 18:00 h, the concentrations of $c a$. 3.5 and $2.4 \mathrm{mg} \mathrm{g}^{-1}(\mathrm{FM})$ were significantly lower and higher, respectively, than those of CK. Malate decarboxylation primarily occurred from 12:00 to $18: 00 \mathrm{~h}$ and the magnitude was only $c a .1 .2 \mathrm{mg} \mathrm{g}^{-1}$ (FM) (Fig. 3A). Thus, lowering of irradiance significantly reduced the nocturnal malate accumulation and delayed the day-time decarboxylation.

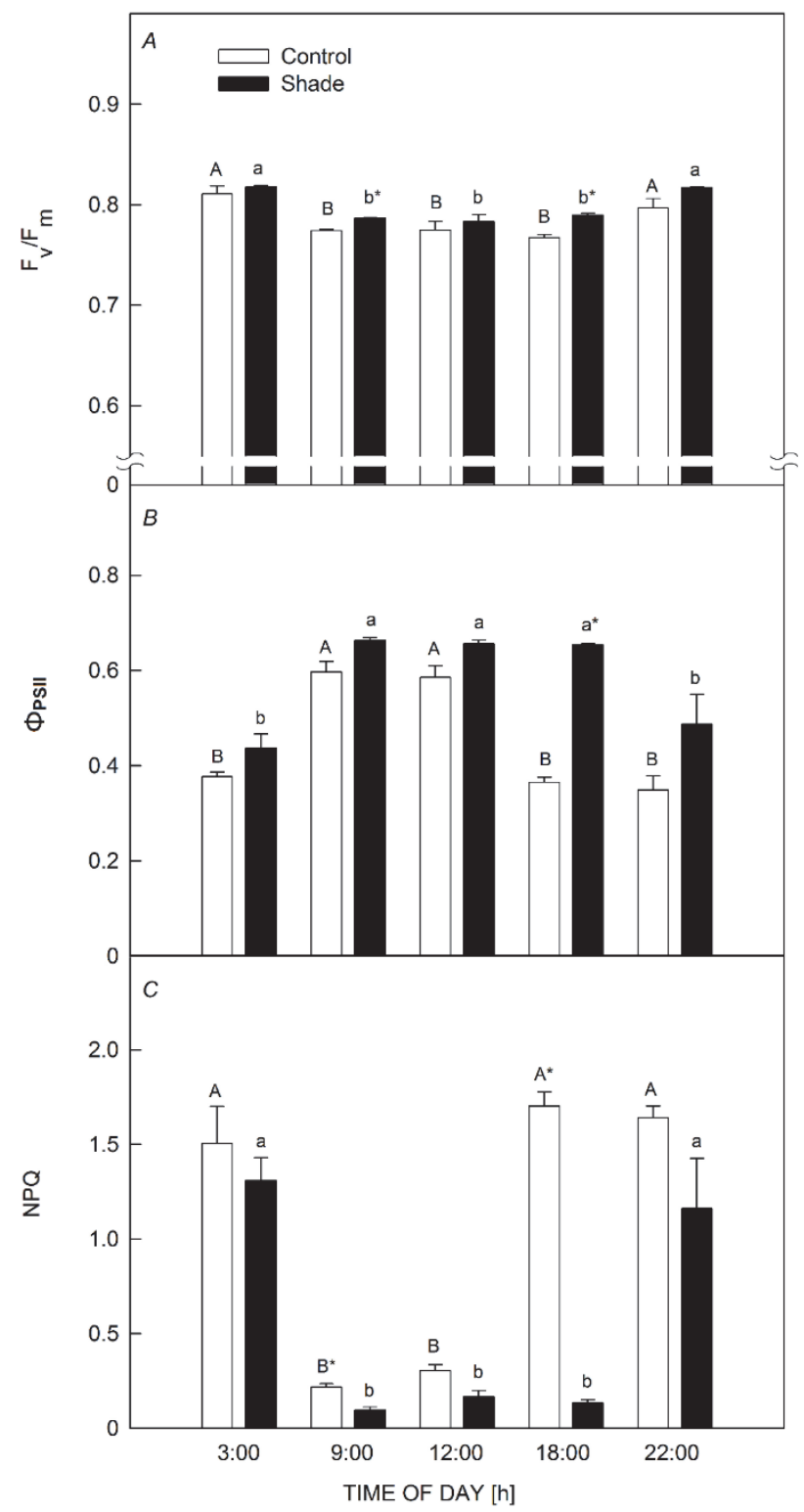

Fig. 1. Day-night fluctuation of the maximum quantum yield $\left(\mathrm{F}_{\mathrm{v}} / \mathrm{F}_{\mathrm{m}}\right)(A)$, actual quantum yield of $\Phi_{\text {PSII }}(B)$, and actual nonphotochemical quenching (NPQ) (C) of Phalaenopsis aphrodite under control (open bars) and shade (full bars) conditions. Data are mean \pm SE of three individual plants. Different capital and lowercase letters show significant difference $(p \leq 0.05)$ in day-night changes under control and shade conditions, respectively. The asterisks indicate significant differences between control and shade treatments at the same sampling time $(p \leq 0.05)$. 


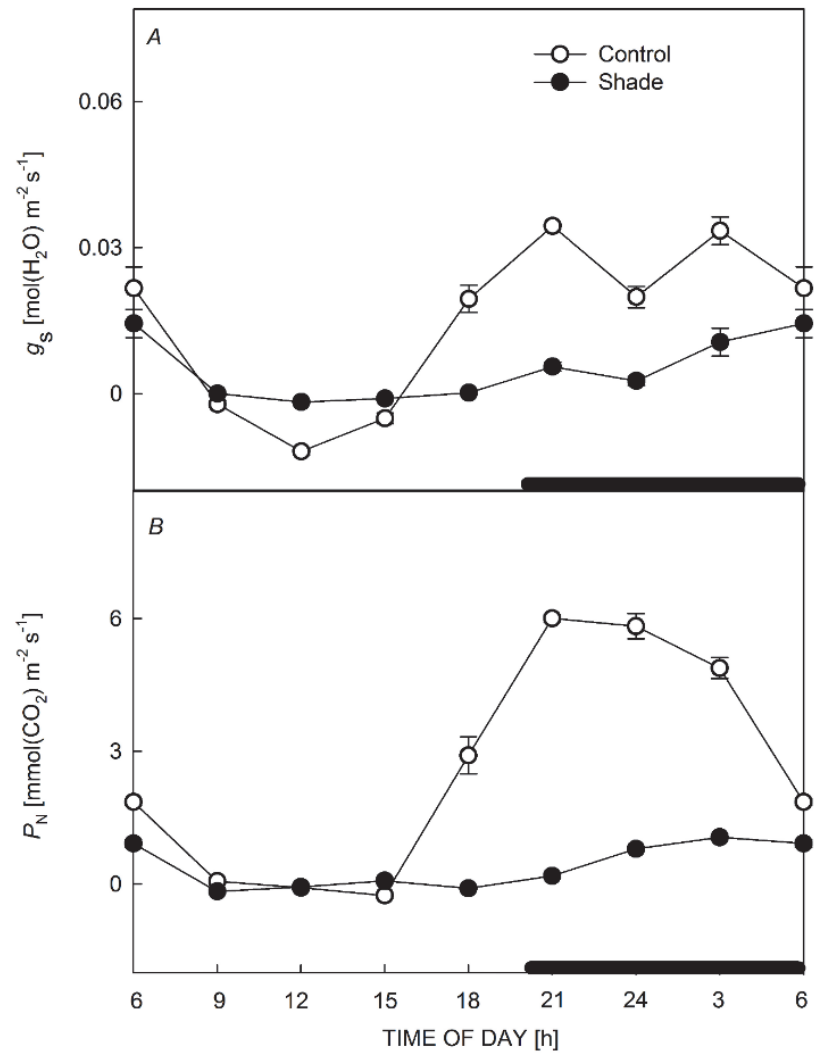

Fig. 2. Day-night fluctuation patterns of $(A)$ stomatal conductance $\left(g_{\mathrm{s}}\right)$ and $(B)$ net $\mathrm{CO}_{2}$ uptake rate $\left(P_{\mathrm{N}}\right)$ of Phalaenopsis aphrodite under control (opened circles) and shade (closed circles) conditions. The dark bars indicate night time. Data are mean \pm SE of three individual plants.

When compared to malate, citrate concentrations remained constant and did not show any day-night fluctuation in both treatments (Fig. 3B). However, lowering of irradiance decreased citrate concentrations approximately to $30-50 \%$ of CK throughout the day (Fig. 3B). Clearly, the metabolic fates of citrate and malate differ in Phalaenopsis exposed to various light intensities.

Carbohydrates: The concentrations of glucose and fructose did not show day-night fluctuation in the leaf and

Table 2. Day-time fluctuation of $\mathrm{O}_{2}$ evolution of Phalaenopsis aphrodite under control and shade conditions. Data are mean \pm SE of four individual plants. Different capital and lowercase letters show significant difference $(p \leq 0.05)$ in day-time changes under control and shade conditions, respectively. The asterisks indicate significant differences between control and shade treatments at the same sampling time $(p \leq 0.05)$.

\begin{tabular}{llrr}
\hline Condition & \multicolumn{3}{l}{$\mathrm{O}_{2}$ evolution $\left[\mu \mathrm{mol} \mathrm{m}^{-2} \mathrm{~s}^{-1}\right]$} \\
& $06: 00 \mathrm{~h}$ & $12: 00 \mathrm{~h}$ & \multicolumn{1}{c}{$18: 00 \mathrm{~h}$} \\
\hline Control & $-17.5 \pm 8.8^{\mathrm{C}}$ & $23.3 \pm 1.3^{\mathrm{A}^{*}}$ & $9.8 \pm 1.6^{\mathrm{B}^{*}}$ \\
Shade & $-33.8 \pm 3.1^{\mathrm{c}}$ & $5.6 \pm 1.0^{\mathrm{a}}$ & $-2.2 \pm 2.9^{\mathrm{b}}$ \\
\hline
\end{tabular}

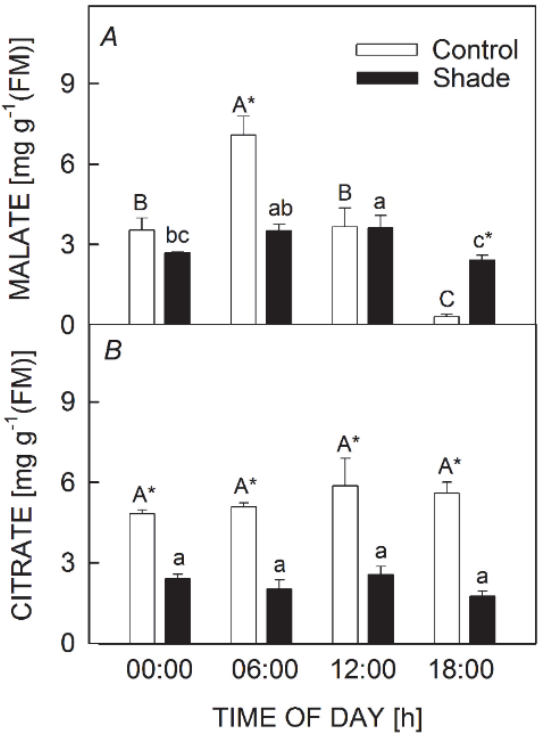

Fig. 3. Day-night fluctuation of malate $(A)$ and citrate $(B)$ contents in Phalaenopsis aphrodite under control- (open bars) and shade (full bars) conditions. Data are mean \pm SE of three individual plants. Different capital and lowercase letters show significant difference $(p \leq 0.05)$ in day-night changes under control and shade conditions, respectively. The asterisks indicate significant differences between control and shade treatments at the same sampling time $(p \leq 0.05)$.

glucose concentrations were always $32-43 \%$ lesser than that of fructose throughout the day during the CK treatment (Fig. 4A,B). The concentration of sucrose increased from $06: 00$ to $12: 00 \mathrm{~h}$, then it was gradually declining until 18:00 h, and slightly increased from 18:00 to $00: 00 \mathrm{~h}$ (Fig. $4 C$ ). This moderate day-night change pattern of sucrose was completely different from that of starch (Fig. 4D). The lowest concentration of starch was detected at 06:00 h, ca. $2.1 \mathrm{mg} \mathrm{g}^{-1}(\mathrm{FM})$, then slightly increased to $4.1 \mathrm{mg} \mathrm{g}^{-1}(\mathrm{FM})$ at $12: 00 \mathrm{~h}$, and greatly increased to peak at 18:00 $\mathrm{h}$ [ca. $\left.13.0 \mathrm{mg} \mathrm{g}^{-1}(\mathrm{FM})\right]$. Clearly, most of the starch deposition appeared from 12:00 to $18: 00 \mathrm{~h}$.

When compared with $\mathrm{CK}$, lowering of irradiance greatly reduced the concentrations of carbohydrates in the leaf and a magnitude of the decrease strongly depended on the sampling time. Glucose increased from sevenfold at 18:00 $\mathrm{h}$ to 20 -fold at $00: 00 \mathrm{~h}$ (Fig. $4 A$ ). Fructose was enhaced from threefold at 06:00 to 11-fold at 00:00 h (Fig. $4 B$ ), sucrose increased from eightfold at $06: 00 \mathrm{~h}$ to 12-fold at 00:00 h (Fig. 4C), while starch accumulated from threefold at 12:00 h to 8-fold at 18:00 h (Fig. 4D). The slight day-night fluctuation for sucrose was abolished and the daytime starch deposition was substantially reduced to only $1.1 \mathrm{mg} \mathrm{g}^{-1}(\mathrm{FM})$. However, fructose showed a slight day-night change in its content and its mean content was higher than that of glucose at all four sampling points, even though the contents of glucose and 


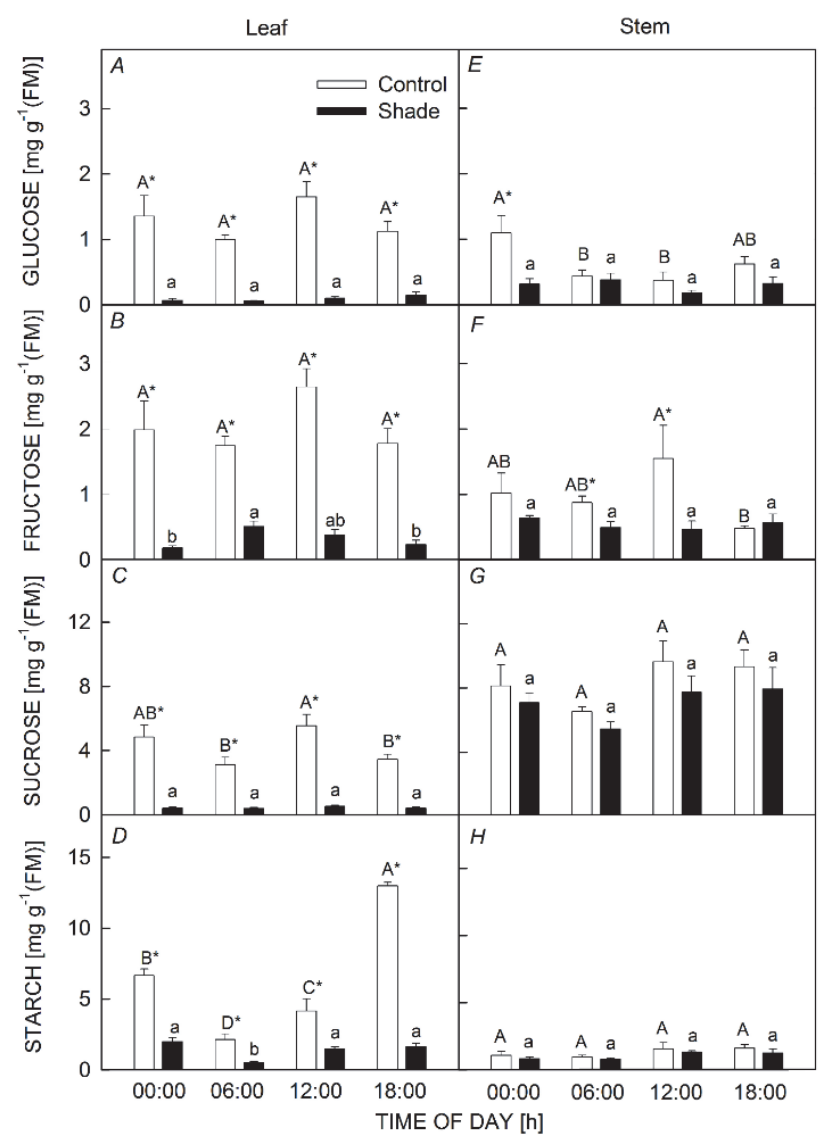

\section{Discussion}

Lower irradiance decreases photosynthetic performance: Numerous studies showed that the photosynthetic rate significantly declined with shading, which resulted in a reduced content of total soluble carbohydrates and lesser fluctuation in the starch concentration (Souza et al. 2004, Chang et al. 2008, Ceusters et al. 2011, Wu et al. 2013). For example, Aechmea 'Maya', an obligate CAM plant, significantly decreased $P_{\mathrm{N}}$, the concentrations of sucrose and starch, and the day-night fluctuations of starch and malic acid under severe irradiance limitation for $6 \mathrm{~d}$ (Ceusters et al. 2011). In our experiment, lowering of irradiance also significantly reduced $g_{\mathrm{s}}$ and delayed stomata opening (Fig. 2A). Likewise, a declined $P_{\mathrm{N}}$ during the night time (Fig. $2 B$ ) and supplemental $\mathrm{CO}_{2}$ via malate decarboxylation during the day time (Fig. $3 A$ ), together with reduced $\mathrm{O}_{2}$ evolution (Table 2), resulted in greatly reduced free glucose, fructose, sucrose, and starch concentrations, and lowered the amplitude of day-time starch deposition in the leaf (Fig. 4A-D).

Compared to carbohydrates, the content of citrate decreased (Fig. $3 B$ ) and the amplitude of night-day change of malate (Fig. $3 A$ ) was lessened by lowering of irradiance. This mitigation of malate and citrate concentration changes also occurred in $A$. 'Maya' under severe irradiance limitation (approximately $15 \%$ of mean control daily
Fig. 4. Day-night fluctuation of glucose $(A, E)$, fructose $(B, F)$, sucrose $(C, G)$, and starch $(D, H)$ contents in leaf $(A-D)$ and stem $(E-H)$ of Phalaenopsis aphrodite under control (open bars) and shade (full bars) conditions. Data are mean \pm SE of three individual plants. Different capital and lowercase letters show significant difference $(p \leq 0.05)$ in day-night changes under control and shade conditions, respectively. The asterisks indicate significant differences between control and shade treatments at the same sampling time $(p \leq 0.05)$.

sucrose remained rather constant. Thus, lowering of irradiance profoundly changed the carbohydrate metabolism in Phalaenopsis leaf.

Despite the marked differences in carbohydrate concentration in leaves under both treatments, during the SH treatment, stems showed the lower content of glucose only at 00:00 h (Fig. $4 E$ ) and that of fructose at 06:00 and 12:00h when compared with CK (Fig. $4 F$ ). However, the contents of sucrose (Fig. 4G) and starch (Fig. 4H) were not affected by the SH treatment and remained rather constant throughout the day as well as the starch content did not show day-night changes in both treatments. Compared to the source leaf, the stem showed lowered glucose, fructose, and starch contents and two- to threefold increased sucrose content in the CK plants. However, under SH, elevations in the glucose and fructose content were slight and varied with the sampling time, but the sucrose content rose from 14-fold at 06:00 $\mathrm{h}$ to 20-fold at 18:00 $\mathrm{h}$.

integrated irradiance) for $6 \mathrm{~d}$ (Ceusters et al. 2011) and in two Phalaenopsis-type orchids under low irradiance (approximately $15 \%$ of mean control irradiance) for 15 weeks (Wu et al. 2013). Citrate and malate are important intermediates of the Krebs cycle that serves as the biochemical hub of the cell and closely relates with respiration capacity. In order to survive, citrate and malate must be maintained at a suitable concentration, even though the carbohydrate contents are severely depleted by limiting irradiance.

Lowering irradiance does not affect the photosynthetic apparatus: Chl $a$ fluorescence analysis has been widely used to assess PSII functioning under abiotic and biotic stresses (Roháček and Barták 1999, Maxwell and Johnson 2000, Baker 2008). Quiles (2005) suggested that typical values for $F_{v} / F_{m}$ were from $0.75-0.85$ for nonstressed plants. When the plants were subjected to $20 \mu \mathrm{mol}$ (photon) $\mathrm{m}^{-2} \mathrm{~s}^{-1}$, the day-night trend of $\mathrm{F}_{\mathrm{v}} / \mathrm{F}_{\mathrm{m}}$ was similar to $\mathrm{CK}$ and values were from $0.76-0.82$ throughout the day (Fig. 1A). Evidently, the PSII apparatus of $P$. aphrodite under low irradiance for six weeks has not been affected, which agrees with Phalaenopsis having the inherent ability to acclimate to low-light arboreal environments because they inhabit tropical rainforests. 
Moreover, $\Phi_{\mathrm{PSII}}$ and NPQ values were always high during the day time (Fig. $1 B$ ) and the night time (Fig. 1C), respectively, for both treatments. High $\Phi_{\text {PSII }}$ during the day time implied that the light absorbed by the PSII antennae could be efficiently utilized in the PSII photochemistry (Genty et al. 1989, Demmig-Adams et al. 1996) and high NPQ during the night time indicated that the excess radiant energy could be efficiently dissipated as heat in the PSII antenna complex (Bilger and Björkman 1990, DemmigAdams et al. 1996). Consistent with $\mathrm{F}_{\mathrm{v}} / \mathrm{F}_{\mathrm{m}}$ (Fig. 1A), $\Phi_{\text {PSII }}$ and NPQ did not show significant differences between the treatments. Thus, it further confirmed that the PSII apparatus of $P$. aphrodite was not affected by low irradiance treatment for six weeks.

The most prominent differences in $\Phi_{\text {PSII }}$ and NPQ between the treatments appeared at 18:00; namely, the stomata were already opened in $\mathrm{CK}$ (Fig. 2A), which resulted in lower $\Phi_{\mathrm{PSII}}$ and higher NPQ (Fig. $1 B, C$ ) when compared with low irradiance treatment where the stomata were still closed (Fig. 2A). In fact, this distinct day-night and reciprocal fluctuation between $\Phi_{\mathrm{PSII}}$ and NPQ was also manifested in $\mathrm{C}_{3}$ plants, such as Helianthus annuus, Vinca major (Demmig-Adams et al. 1996), Phaseolus radiates (Yang et al. 2004), $\mathrm{C}_{4}$ plant, such as Setaria italic (Yang et al. 2004), and CAM plants, such as Clusia hilariana (Franco et al. 1999) and Phalaenopsis (Pollet et al. 2009). Pollet et al. (2009) explained that low $\Phi_{\mathrm{PSII}}$ and high NPQ at the transition from day to night was closely associated with the inactivation of the Calvin cycle. Indeed, in our CK plants, the sucrose concentration was lower at 18:00 than that at 12:00 h (Fig. 4C). However, the hexose content was not changed (Fig. $4 A$ and $B$ ) and the starch amount greatly increased from 12:00 to 18:00 h (Fig. 4D). The starch content could increase due to the increase in the amount of accessible precursors for starch biosynthesis during this period, including $\mathrm{CO}_{2}$ source derived from ambient (Fig. $2 B$ ) and malate decarboxylation (Fig. $3 A$ ), the carbonskeleton source derived from malate decarboxylation (Fig. 3A), sucrose degradation (Fig. $4 C$ ), and the high rate of light reaction as evidenced by the high $\mathrm{O}_{2}$ evolution (Table 2).
Lowering irradiance does not affect the sucrose concentration in the stem: One of the most intriguing findings is that lowering irradiance did not affect the sucrose concentration in the stem and its concentrations were unusually higher than that in the leaf throughout the day (Fig. $4 C, G$ ). Due to the dormant spike bud of Phalaenopsis directly connected with the stem, the correlation between the spike emergence and sucrose concentration is seemingly not so tight, even though many studies have mentioned a positive relationship between sucrose concentration and spiking of Phalaenopsis (Konow and Wang 2001, Kataoka et al. 2004, Guo and Lee 2006, Tsai et al. 2008, Wu et al. 2013).

Sucrose is an important compatible solute (Wang et al. 2000, Roussos et al. 2010). It is explicable that the different leaves of Phalaenopsis under a limiting irradiance maintain only a threshold content of sucrose for survival and transport the surplus into the stem to sustain the viability of the dormant spike bud(s). In fact, such a high sucrose content in the stem also occurs after warmnight treatment, which is also a strategy for delaying spike development (Liu et al. 2013). Hence, the shortened stem of Phalaenopsis plays a storage function having a strong sink activity to store enough sucrose from all source leaves (Liu et al. 2013), to supply a carbon source for spike development when Phalaenopsis is under suitable flowering conditions, and to maintain the viability of dormant spike bud(s) when Phalaenopsis is exposed to a spiking inhibition condition.

Conclusion: We reported that lowering of irradiance greatly decreased photosynthetic performance and delayed the spiking, but did not affect the potential function of photosynthetic apparatus and retained enough supply of sucrose in the stem, where the spiking takes place. Our results confirmed that Phalaenopsis possesses the inherent ability to acclimate to low-light arboreal environments. We suggested that the correlation between sucrose and spiking was not apparently so tight and the crucial factors for spiking of Phalaenopsis remain to be ascertained.

Open Access This article is distributed under the terms of the Creative Commons Attribution License which permits any use, distribution, and reproduction in any medium, provided the original author(s) and the source are credited.

\section{References}

Baker N.R.: Chlorophyll fluorescence: A probe of photosynthesis in vivo. - Annu. Rev. Plant Biol. 59: 89-113, 2008.

Bilger W., Björkman O.: Role of the xanthophylls cycle in photoprotection elucidated by measurements of light-induced absorbance changes, fluorescence and photosynthesis in Hedera canariensis. - Photosynth. Res. 25: 173-185, 1990.

Callaway T.R., Martin S.A., Wampler J.L. et al.: Malate content of forage varieties commonly fed to cattle. - J. Dairy Sci. 80: 1651-1655, 1997.

Ceusters J., Borland A.M., Godts C. et al.: Crassulacean acid metabolism under severe light limitation: a matter of plasticity in the shadows? - J. Exp. Bot. 62: 283-291, 2011.

Chang X., Alderson P.G., Wright C.J.: Solar irradiance level alters the growth of basil (Ocimum basilicum L.) and its content of volatile oils. - Environ. Exp. Bot. 63: 216-223, 2008.

Chen W.H., Tseng Y.C., Liu Y.C. et al.: Influence of cool-night on the photosynthetic efficiency and the nonstructural carbohydrate and organic acid pools in Phalaenopsis aphrodite. - Plant Cell Rep. 27: 1667-1675, 2008.

Chugh S., Guha S., Rao I.U.: Micropropagation of orchids: 
A review on the potential of different explants. - Sci. Hortic.Amsterdam 122: 507-520, 2009.

Demmig-Adams B., Adams III W.W., Baker D.H. et al.: Using chlorophyll fluorescence to assess the fraction of absorbed light allocated to thermal dissipation of excess excitation. - Physiol. Plantarum 98: 253-264, 1996.

Endo M., Ikusima I.: Diurnal rhythm and characteristics of photosynthesis and respiration in the leaf and root of a Phalaenopsis plant. - Plant Cell Physiol. 30: 43-47, 1989.

Endo M., Ikusima I.: Changes in concentrations of sugars and organic acids in the long-lasting flower clusters of Phalaenopsis. - Plant Cell Physiol. 33: 7-12, 1992.

Franco A.C., Herzog B., Hübner C. et al.: Diurnal changes in chlorophyll a fluorescence, $\mathrm{CO}_{2}$-exchange and organic acid decarboxylation in the tropical CAM tree Clusia hilariana. Tree Physiol. 19: 635-644, 1999.

Genty B., Briantais J.M., Baker N.R.: The relationship between quantum yield of photosynthetic electron transport and quenching of chlorophyll fluorescence. - Biochim. Biophys. Acta 990: 87-92, 1989.

Guo W.J., Lee N.: Effect of leaf and plant age and day/night temperature on net $\mathrm{CO}_{2}$ uptake in Phalaenopsis amabilis var. Formosa. - J. Am. Soc. Hortic. Sci. 131: 320-326, 2006.

Hisamatsu T., Sugiyama Y., Kubota S., Koshioka M.: [Delaying anthesis by dark treatment in Phalaenopsis.] - J. Jap. Soc. Hortic. Sci. 70: 264-266, 2001. [In Japanese]

Kataoka K., Sumitomo K., Fudano T., Kawase K.: Changes in sugar content of Phalaenopsis leaves before floral transition. Sci. Hortic.-Amsterdam 102: 121-132, 2004.

Konow E.A., Wang Y.T.: Irradiance levels affect in vitro and greenhouse growth, flowering, and photosynthetic behavior of a hybrid Phalaenopsis orchid. - J. Am. Soc. Hortic. Sci. 126: 531-536, 2001.

Kubota S., Yoneda K.: [Effects of light intensity preceding day/night temperatures on the sensitivity of Phalaenopsis to flower.] - J. Jap. Soc. Hortic. Sci. 62: 595-600, 1993. [In Japanese]

Liu C.H., Liu Y.C., Chen W.H., Wang H.L.: [Effects of underneath-bench shading treatment on spiking and flowering of Doritaenopsis.] - J. Agr. Assoc. Taiwan 11: 501-513, 2010. [In Chinese]

Liu Y.C., Tseng K.M., Chen C.C. et al.: Warm-night temperature delays spike emergence and alters carbon pool metabolism in the stem and leaves of Phalaenopsis aphrodite. - Sci. Hortic.Amsterodam 161: 198-203, 2013.

Maxwell K., Johnson G.N.: Chlorophyll fluorescence. - A practical guide. - J. Exp. Bot. 51: 659-668, 2000.
Osmond C.B.: Crassulacean acid metabolism: a curiosity in context. - Annu. Rev. Plant Physio. 29: 379-414, 1978.

Pollet B., Steppe K., Van Labeke M.C., Lemeur R.: Diurnal cycle of chlorophyll fluorescence in Phalaenopsis. - Photosynthetica 47: 309-312, 2009.

Pollet B., Vanhaecke L., Dambre P. et al.: Low night temperature acclimation of Phalaenopsis. - Plant Cell Rep. 30: 1125-1134, 2011.

Popp M., Janett H.P., Lüttge U., Medina E.: Metabolite gradients and carbohydrate translocation in rosette leaves of CAM and C3 bromeliads. - New Phytol. 157: 649-656, 2003.

Quiles M.J.: Photoinhibition of photosystem I and II using chlorophyll fluorescence measurements. - J. Biol. Edu. 39: 136-138, 2005

Roháček K., Barták M.: Technique of the modulated chlorophyll fluorescence: basic concepts, useful parameters, and some applications. - Photosynthetica 37: 339-363, 1999.

Roussos P.A., Denaxa N.K., Damvakaris T. et al.: Effect of alleviating products with different mode of action on physiology and yield of olive under drought. - Sci. Hortic.Amsterodam 125: 700-711, 2010.

Sakanishi Y., Imanishi H., Ishida G.: [Effect of temperature on growth and flowering of Phalaenopsis amabilis.] - Bull. Univ. Osaka Prefecture, B 32: 1-9, 1980. [In Japanese]

Souza A., de Paula A., Figueiredo-Ribeiro R.C.L.: Effects of irradiance on non-structural carbohydrates, growth, and hypoglycemic activity of Rhynchelytrum repens (Willd.) C.E. Hubb. (Poaceae). - Braz. J. Biol. 64: 697-706, 2004.

Tsai W.T., Wang Y.T., Lin H.L.: Alternating temperature affects spiking of a hybrid Phalaenopsis. - Acta Hortic. 766: 307-314, 2008

Wang H.L., Lee P.D., Chen W.L. et al.: Osmotic stress-induced changes of sucrose metabolism in cultured sweet potato cells. - J. Exp. Bot. 51: 1991-1999, 2000.

Wang Y.T.: Phalaenopsis light requirement during the induction of spiking. - HortScience 30: 59-61, 1995.

Wang Y.T.: Phalaenopsis light requirements and scheduling of flowering. - Orchids 66: 934-939, 1997.

Wu P.H., Liu C.H., Tseng K.M. et al.: Low irradiance alters carbon metabolism and delays flower stalk development in two orchids. - Biol. Plantarum 57: 764-768, 2013.

Yang J.D., Zhao H.L., Zhang T.H.: Diurnal patterns of net photosynthetic rate, stomatal conductance, and chlorophyll fluorescence in leaves of field-grown mungbean (Phaseolus radiatus) and millet (Setaria italica). - J. Crop Hortic. Sci. 32: 273-279, 2004. 